\title{
LOS MORTEROS CENTROITÁLICOS PROCEDENTES DE LOS RELLENOS CONSTRUCTIVOS DEL ANFITEATRO DE SEGOBRIGA. REVISIÓN CRONOLÓGICA
}

\author{
CENTRAL-ITALIC MORTARS FROM THE CONSTRUCTIVE FILLER MATERIALS IN THE \\ AMPHITEATRE OF SEGOBRIGA. CHRONOLOGICAL REVIEW
}

\author{
ROSARIO CEBRIÁN FERNÁNDEZ \\ Universidad Complutense de Madrid \\ IGNACIO HORTELANO UCEDA \\ Parque Arqueológico de Segobriga
}

\begin{abstract}
Resumen
La excavación arqueológica realizada en el período 2011-2013 en el anfiteatro de Segobriga ha documentado treinta y seis ejemplares de morteros de procedencia centroitálica. Su hallazgo en vertidos de nivelación y rellenos constructivos de cronología vespasianea aporta una fecha ante quem para la comercialización en la ciudad de la forma Dramont D 2, fase 3. Los sellos conservados en algunos morteros mencionan a varios alfareros y propietarios de los talleres en los que se fabricaron, entre ellos, Statius Marcius Suavillus, un officinator sólo documentado hasta la fecha en una estampilla sobre dolium hallada en Roma (CIL XV 1291).
\end{abstract}

Palabras clave. Morteros itálicos, sellos epigráficos, anfiteatro, Segobriga.

\begin{abstract}
The archaeological excavations carried out in the Amphitheater of the Roman city of Segobriga between the years 2011-2013 have provided a set of thirty-six Italian mortaria. Since they were discovered inside some constructive filer materials dating from the Vespasianean age, this date should be considered a terminus ante quem for their commercialisation in the city, especially that of the form Dramont D 2 Phase 3. The stamps on these mortars mention several potters and owners of the workshops in which they were made, including Statius Marcius Suavillus, an officinator only known to date by a stamp on dolium found in Rome (CIL XV 1291).
\end{abstract}

Key words. Italic mortaria, epigraphic stamps, amphitheater, Segobriga.

Para citar este artículo / To cite this article: Cebrián Fernández, R. e Hortelano Uceda. I. (2016). Los morteros centroitálicos procedentes de los rellenos constructivos del anfiteatro de Segobriga. Revisión cronológica. Lucentum, $X X X V$, 141-154. doi: 10.14198/LVCENTVM2016.35.07

Para enlazar con este artículo / To link to this article: http://dx.doi.org/10.14198/LVCENTVM2016.35.07 


\title{
LOS MORTEROS CENTROITÁLICOS PROCEDENTES DE LOS RELLENOS CONSTRUCTIVOS DEL ANFITEATRO DE SEGOBRIGA. REVISIÓN CRONOLÓGICA
}

\author{
CENTRAL-ITALIC MORTARS FROM THE CONSTRUCTIVE FILLER MATERIALS IN THE \\ AMPHITEATRE OF SEGOBRIGA. CHRONOLOGICAL REVIEW
}

\author{
ROSARIO CEBRIÁN FERNÁNDEZ \\ Universidad Complutense de Madrid \\ IGNACIO HORTELANO UCEDA \\ Parque Arqueológico de Segobriga
}

Hace unos años presentamos el catálogo de los morteros de origen centroitálico hallados en las excavaciones del período 1982-2010 en Segobriga (Cebrián y Hortelano, 2011, 127-142). El establecimiento de la cronología de los cuarenta morteros procedentes de distintas áreas del yacimiento arqueológico se llevó a cabo a partir de la evolución tipológica establecida por C. Aguarod (1991, 137-141) para los ejemplares de la forma Dramont D 1 y D 2 de la Tarraconense, pues la datación de los contextos en los que fueron localizados correspondían a momentos posteriores. Sólo un mortero Dramont D 1, documentado en las viviendas cesarianas excavadas en la terraza superior a la basílica del foro en 2010, podía fecharse entre finales del siglo I e inicios del II (Cebrián y Hortelano 2011, nº. 36), mientras que la forma Dramont D 2, fase 3, parecía llegar a la ciudad a partir de época flavia, asociada a otras importaciones itálicas (Cebrián y Hortelano, 2011, $\mathrm{n}^{\text {}}$. 3-5, 7, 31 y 32).

Sin embargo, los trabajos de excavación en relación con el proyecto de consolidación y adecuación del anfiteatro romano de Segobriga. $1^{\text {a }}$ fase - cavea sur realizados entre noviembre de 2011 y mayo de 2013 recuperaron un conjunto de treinta y siete morteros centroitálicos, principalmente de la forma Dramont D 2 , fase 3 , en vertidos de nivelación y rellenos constructivos del anfiteatro de cronología vespasianea.

Estas excavaciones arqueológicas han proporcionado una cronología en la década de los 70 del siglo I para el acondicionamiento de los accesos al graderío sur del anfiteatro segobrigense, ya apuntada por M. Almagro-Gorbea y A. Lorrio (1989, 129-145), a partir del estudio de los materiales cerámicos hallados en los niveles situados entre el denominado muro oeste y el muro sur del anfiteatro.

De esta manera, contamos con una fecha ante quem para la llegada a Segobriga de los morteros Dramont D 2, con características morfológicas correspondientes a la fase 3. Sin embargo, algunas consideraciones sobre este tipo de material permitirían precisar una cronología postclaudiana para el inicio de su comercialización. Por un lado, el uso de este tipo de recipiente en la preparación de alimentos, desde su función original en la maceración del cereal a partir del siglo VII a. C. hasta servir para la mezcla de ingredientes en la elaboración de papillas y salsas en época romana (Dosi y Schanell, 1984, 126), permite considerar al mortero como un recipiente indispensable en las cocinas, con una vida útil de 20 o 30 años, teniendo en cuenta además su robustez y, por tanto, su resistencia. Su principal función doméstica conllevó que se tratase de un elemento cerámico no excesivamente sujeto a modas y caro en el caso de importaciones, a pesar de que desde finales del siglo II a. C. los morteros campanos serán imitados y producidos en el valle del Ebro - morteros tipo Azaila-y distribuidos ampliamente por el medio Ebro y Bajo Aragón (Beltrán Lloris, 2002 y 2003) y los morteros con estrías de fricción fabricados en talleres béticos y lusitanos con el fin de abastecer los mercados del sur de Hispania durante época altoimperial (Peinado, 2011, 283-302). Por otro lado, los morteros suelen aparecer fracturados y fragmentados en contextos arqueológicos en los que el objeto ya se encuentra amortizado, por lo que la datación de su fabricación y comercialización no concuerda con la del estrato en el que se encuentran sino que debe considerarse necesariamente anterior.

Por ello, los morteros centroitálicos hallados en Segobriga pueden fecharse entre finales de época de Claudio y el reinado de Nerón, siendo definitivamente amortizados en los vertidos constructivos del anfiteatro de época flavia.

Cinco de los sellos identificados sobre este material mencionan a varios officinatores de la gens Domitia y Calpetana del entorno de Roma, lo que corrobora la comercialización de su producción en Hispania con anterioridad a época de Vespasiano (Fig. 1). Junto a ellos, dos sellos de un mismo mortero, impresos con la misma matriz ( $\mathrm{n}^{\circ} .49$ del catálogo), y un tercero $\left(\mathrm{n}^{\circ} .77\right.$ del catálogo) mencionan en genitivo a dos propietarios 

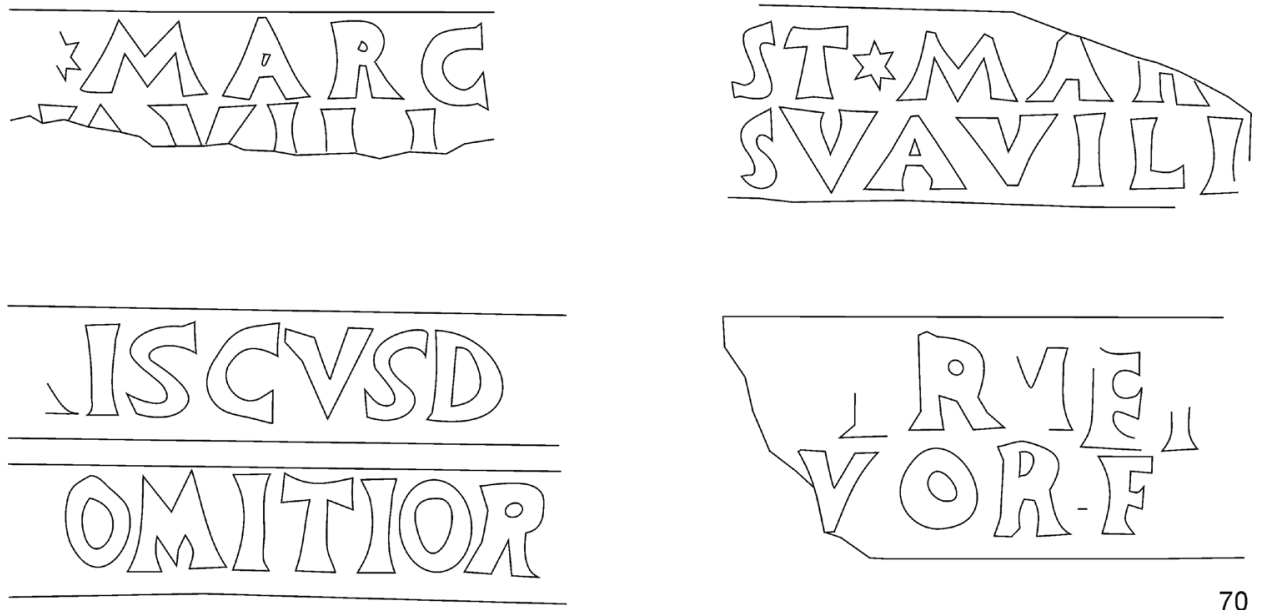

69
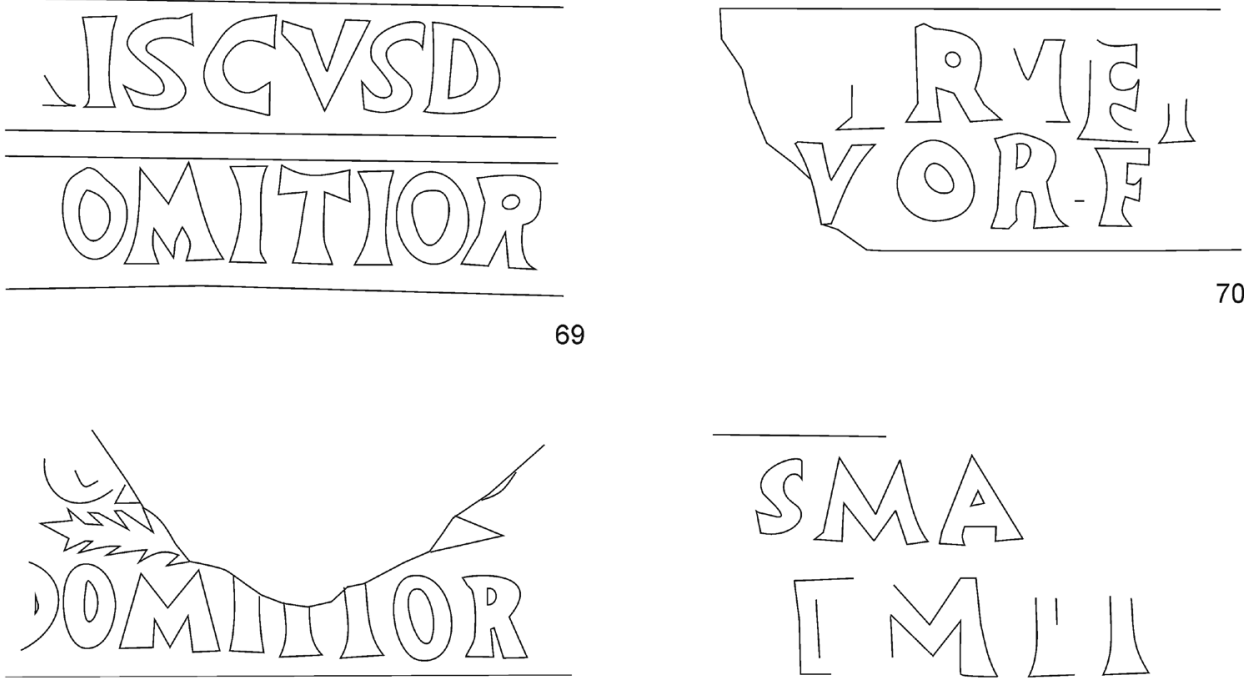

70

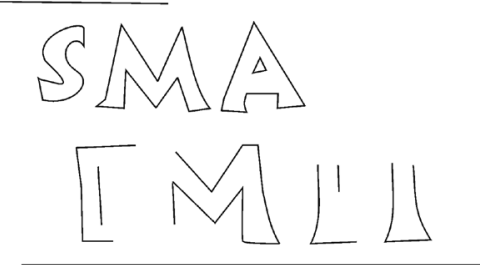

77

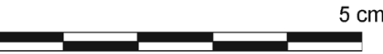

Figura 1: Estampillas de los morteros centroitálicos hallados en las excavaciones realizadas al sur del anfiteatro de Segobriga. El número de la pieza corresponde al del catálogo.

de alguna de las officinae de la figlina Marciana: Statius Marcius Svavillus, documentado en una estampilla circular sobre dolium (CIL XV 1291) y Statius Marcius Demetrius, cuya producción sellada incluyó tanto morteros, sarcófagos, material latericio y dolia (Aguarod, 1991, 171). Otras estampillas de los Statii Marcii documentados en Segobriga, mencionan a Celer y Restitutus (Cebrián y Hortelano, 2011, nº. 1 $\left.\mathrm{y} \mathrm{n}^{\circ} .29\right)$.

\section{EL CONTEXTO ARQUEOLÓGICO. LOS RE- LLENOS CONSTRUCTIVOS DEL ANFITEA- TRO DE SEGOBRIGA}

La mayor parte de los morteros centroitálicos procede del área de excavación arqueológica situada entre la muralla y el muro meridional del anfiteatro donde se localizó un vertido coetáneo de rellenos relacionado con el acondicionamiento exterior del edificio. Para el acceso del público al graderío sur del anfiteatro a través de las puertas exteriores, fue necesario demoler parte de la antigua muralla y rellenar el espacio que quedaba entre ella y el muro del anfiteatro, consiguiendo así sobreelevar la cota de circulación hasta igualar el nivel de la ronda exterior y los vomitorios.
Aquel espacio fue aprovechado como vertedero de escombros. Su datación se establece con precisión gracias al abundante material cerámico recuperado en su excavación, unos 90.000 fragmentos caracterizados por su homogeneidad. La horquilla cronológica abarca desde Tiberio hasta Vespasiano, abundando especialmente los materiales de época de Nerón (Fig. 2).

Los servicios de mesa están compuestos fundamentalmente por producciones gálicas de terra sigillata siendo las itálicas escasas y de carácter claramente residual y las hispánicas singularmente reducidas y correspondientes en su mayoría a época flavia. La cronología se establece a partir de la presencia de formas que integran los servicios de época flavia como la copa Drag 35, el plato Drag 36 y el vaso Herm 9, las copas Drag 46-Herm 8a y Drag 24/25a, el cuenco Curle 11, los vasos Dech 67 y Drag 33 A2, el plato Drag 18b o el bol Drag 37, siendo significativa la ausencia de producciones algo más avanzadas como las copas Ritt 8c y Drag 27c, el plato Drag 51-Curle 15 o los servicios completos D y F de Vernhet. La aparición de diversos ejemplares de terra sigillata marmorata y de labios decorados a la barbotina con hojas de agua refuerza la datación. Se documentan también decoraciones representativas del denominado período de transición, caracterizadas por su barroquismo, 


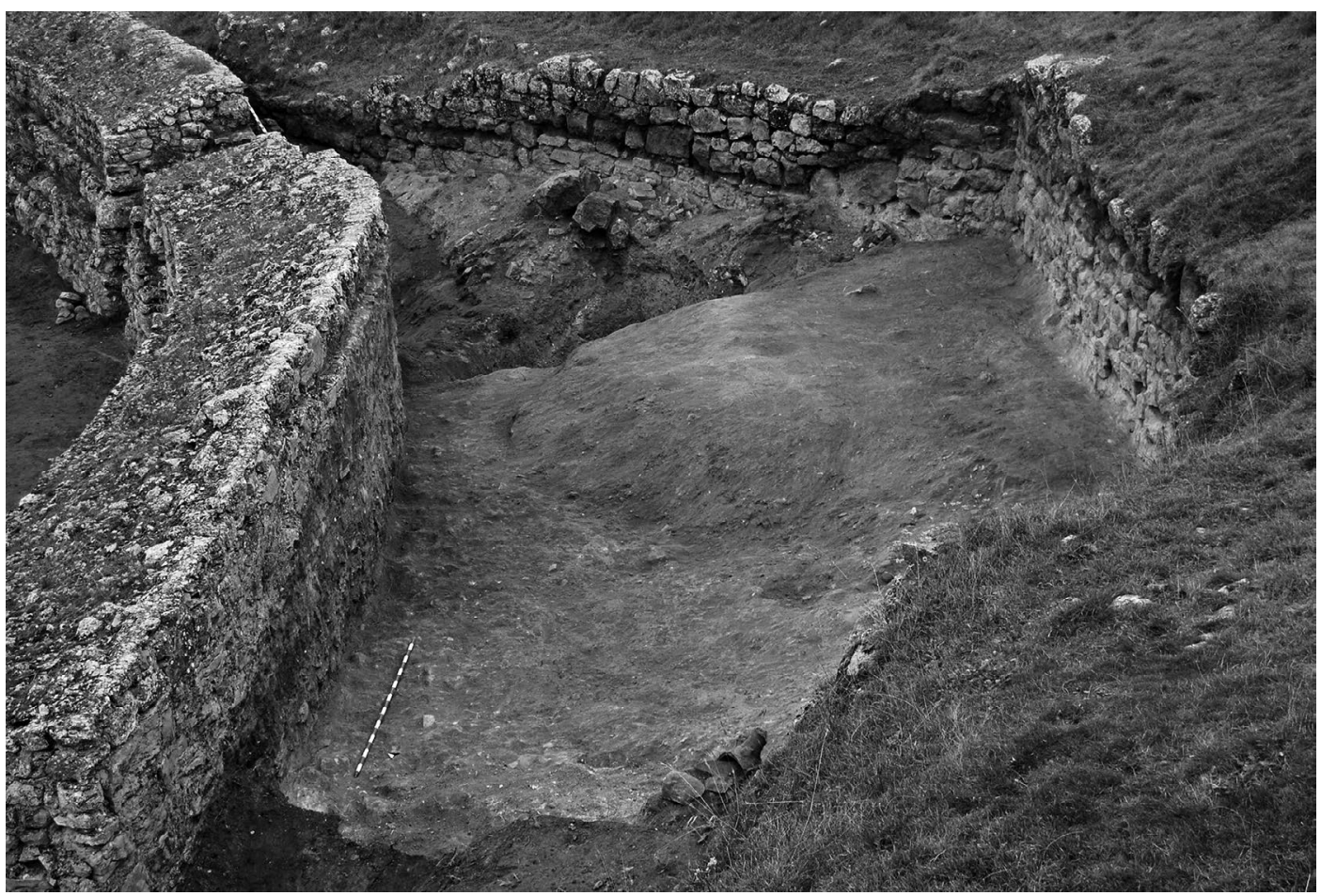

Figura 2: Vista general de los vertidos realizados en el área situada entre la muralla y el anfiteatro durante el proceso de excavación. 29 de noviembre de 2011.

la división de los esquemas decorativos en paneles mediante líneas horizontales y las representaciones vegetales con hojas y rosetas rematando largos tallos ondulados, arbustos, matojos, animales en carrera, perros y conejos en escenas de persecución, áreas estrigiladas, metopas con hojas imbricadas, figuras humanas de gladiadores o sátiros. Junto a estos materiales se identifican también abundantes vasos de paredes finas entre los que destacan los producidos en cáscara de huevo y los engobados procedentes de los talleres del valle del Ebro.

El conjunto se completa con abundante cerámicas común y pintada de tradición celtibérica, ajuares de cocina de producción local e importada, principalmente fuentes de engobe interno rojo pompeyano, contenedores, dolia y más de 600 fragmentos de vidrio. Junto a escasos fragmentos de vidrio plano se localizó un número importante de placas de lapis specularis para el cerramiento de ventanas.

En su excavación también se halló un nivel arqueológico (UE 16061), que contenía materiales de derribo de una o varias estancias de una vivienda decorada con pintura mural. El esquema pictórico corresponde al tercer estilo pompeyano que, cronológicamente, se enmarca entre inicios del reinado de Augusto y los años 40-50 d. C. Se distinguen tres zonas en sentido horizontal: un zócalo corrido o continuo, sobre el que se extiende la zona media de la pared dividida en espacios verticales y la parte alta con colores claros y decorados con elementos arquitectónicos estilizados -dentículos y cyma lésbica-. En la transición entre la zona media y superior predominan los fondos negros decorados con cenefas con detalles florales en miniatura que enmarcan racimos de uva y ciruelas.

El lote de ánforas recuperado del vertedero constituye un excelente indicativo de la actividad comercial del momento, habiéndose identificado envases que transportaban vino procedente de la Península Itálica, del Mediterráneo Oriental y de las costas tarraconenses, defrutum del sur de la Bética, aceite del valle del Guadalquivir, salazones y preparados de pescado de la Bética y de Lusitania, alumbre de las costas adriáticas y frutos secos del área sirio-palestina.

No se identificaron fosas, silos u otro tipo de alteraciones del paquete estratigráfico excepto un sondeo arqueológico previo realizado en la campaña de los años 1986 y 1987 (cuadrícula D, sector 8) y las relacionadas con los robos de sillares de los arcos de dos de los vomitorios de acceso al graderío sur del anfiteatro $\left(3^{\circ}\right.$ y $4^{\circ}$ vomitorio), donde se localizó un mortero de la forma Dramont D 2, fase 3 .

Por otro lado, otros dos morteros fueron hallados en un sondeo estratigráfico llevado a cabo en el extremo oeste de la summa cavea con la finalidad de verificar la secuencia estratigráfica en esta zona del edificio y de documentar el trasdós de la cimentación del muro del balteus. Se documentó un conjunto de rellenos constructivos (UUEE 16089 y 16090) relacionados con la edificación del anfiteatro que habían sido vertidos contra la cara externa -sur- del balteus (UE 16055). Contenían materiales cerámicos escasos pero análogos a los recuperados en los niveles constructivos existentes al sur del anfiteatro, lo que confirma su equivalencia y coetaneidad. 


\section{CATÁLOGO}

Los morteros centroitálicos procedentes de las excavaciones arqueológicas en Segobriga suman un total de setenta y siete ejemplares, convirtiéndose en uno de los conjuntos más importantes hallados en la Península Ibérica. De los treinta y siete morteros recuperados en las excavaciones del anfiteatro de Segobriga, tan
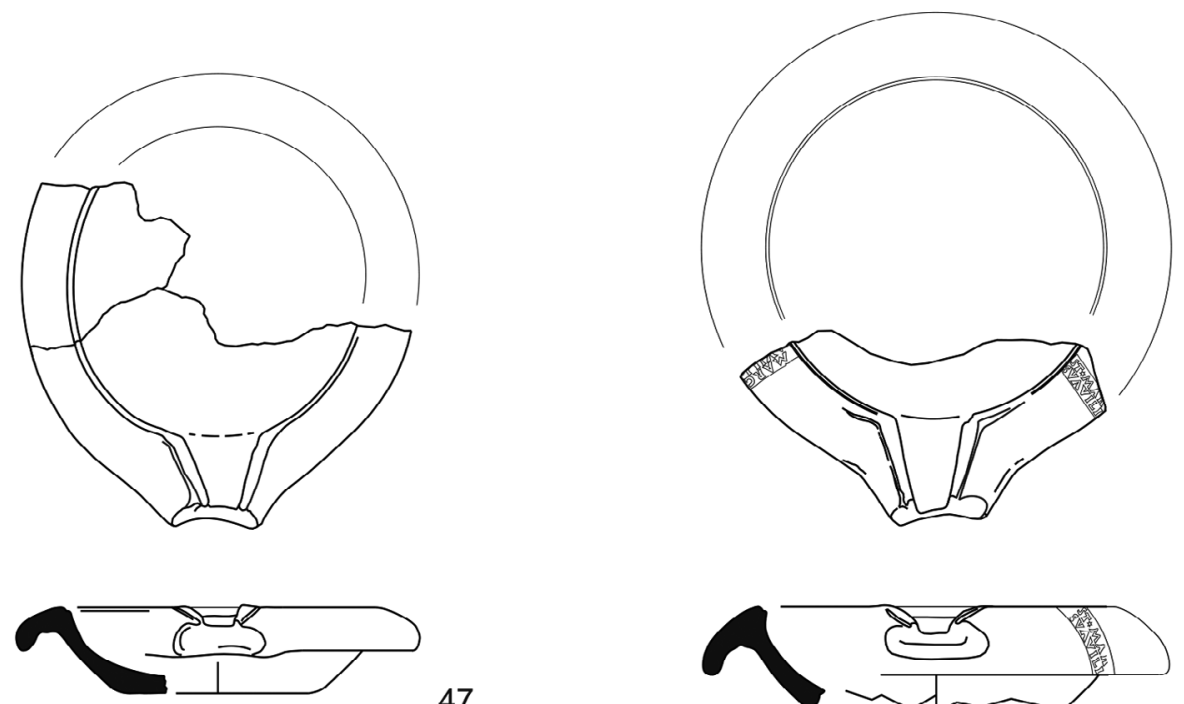

47
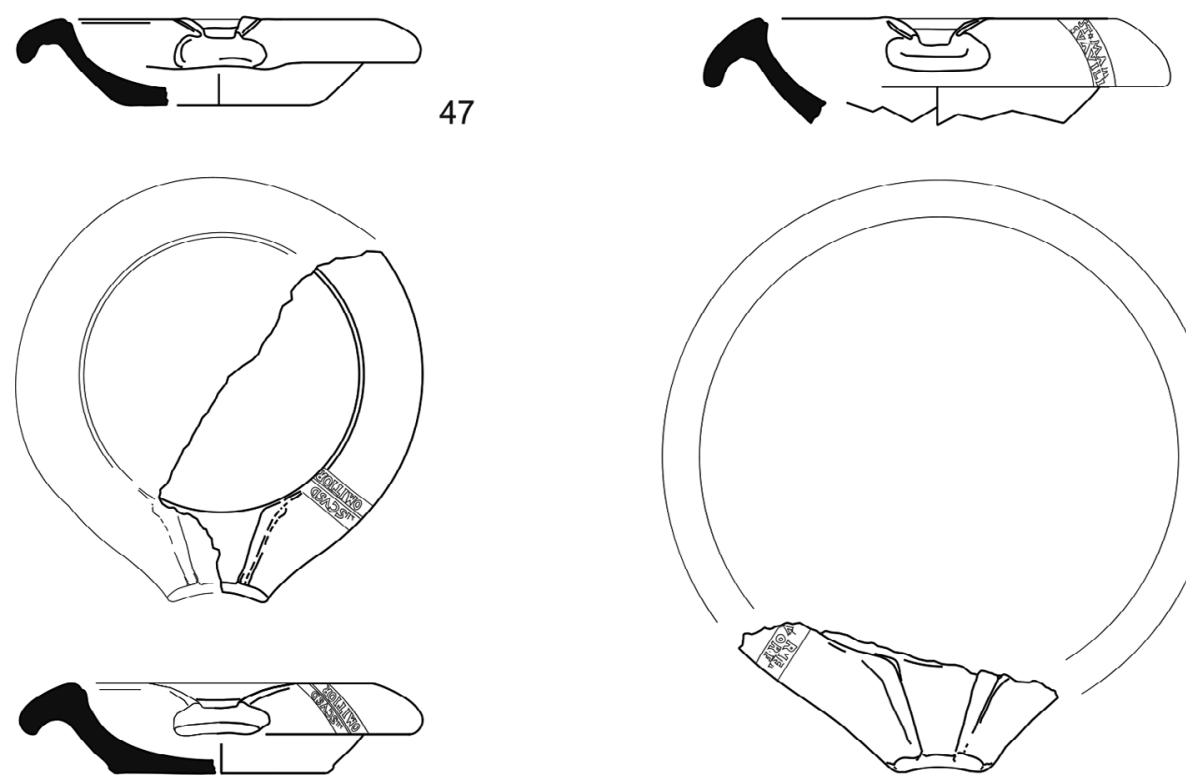

69
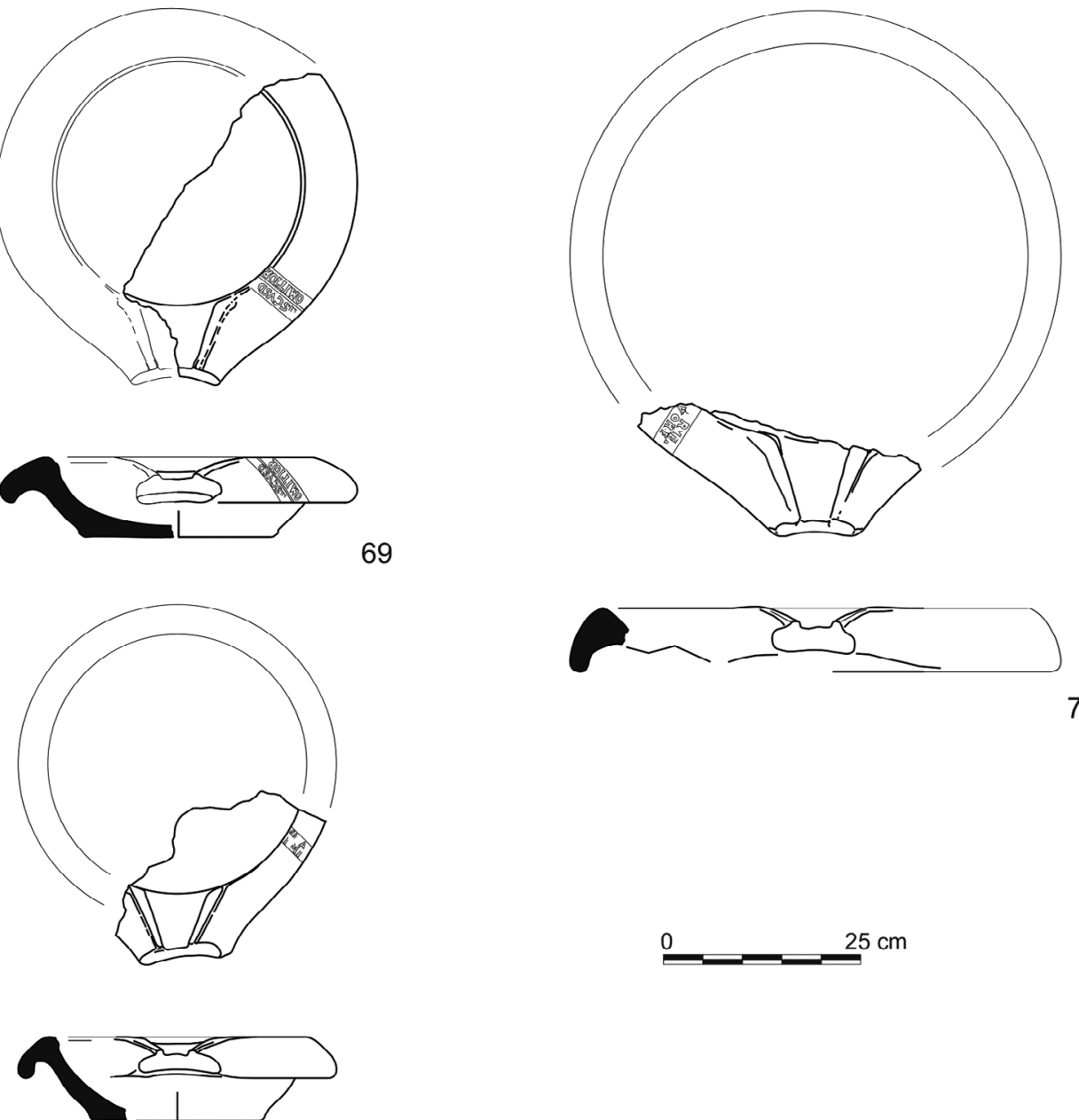

77

Figura 3: Morteros de producción centroitálica hallados en la excavación del anfiteatro de Segobriga. El número de la pieza corresponde al del catálogo. 
sólo seis ejemplares corresponden a la variante Dramont D 1, mientras que el resto pertenecen al tipo Dramont D 2, fase 3, con la única excepción de una pieza que se adscribe a la fase 1 (Figs. 3 y 4 ).

A continuación, presentamos su catálogo, siguiendo con la numeración de la publicación anterior:

41. $\mathrm{N}^{\circ}$. de registro arq.: 11-16004-033. Nivel constructivo al sur del anfiteatro. Relleno de tierra suelta de textura arenosa, heterogénea, con manchas negruzcas pero de coloración principalmente rosada-rojiza. Prácticamente sin piedras, excepto en áreas muy puntuales. Presencia de concentraciones de cerámica y de algunos fragmentos de pintura mural.

Forma Dramont D 2, fase 1. Fragmento de borde de mortero que sólo conserva el inicio del ala, maciza y algo colgante, y el arranque de la pared, de desarrollo hemisférico. La cara interna del vaso conserva restos de su recubrimiento abrasivo arenoso muy erosionado. Pasta rugosa de color rosado amarillento con abundante desgrasante formado por partículas brillantes, rojas y negras. Superficie lisa de color amarillento. Conservación: mala. Diámetro máx.: no determinado; diámetro boca: $26 \mathrm{~cm}$.

42. $\mathrm{N}^{\mathrm{o}}$. de registro arq.: 11-16004-034. Nivel constructivo al sur del anfiteatro. Se localizó en el mismo nivel arqueológico que el número 41 del catálogo.

Forma Dramont D 2, fase 3. Fragmento de borde y cuerpo de mortero con gran ala colgante, estría marcada en el inicio del vaso y pared de desarrollo hemisférico algo abierto con su cara interna recubierta por abundante abrasivo de tipo arenoso. Arcilla muy fina de color rosado rojizo con desgrasante dorado, rojizo y arenoso. Engobe pálido de textura untuosa. Conservación: buena. Diámetro máx.: $32 \mathrm{~cm}$; diámetro boca: $25 \mathrm{~cm}$.

43. $\mathrm{N}^{\mathrm{o}}$. de registro arq.: 11-16005-125. Nivel constructivo al sur del anfiteatro. Relleno grisáceo, suelto y arenoso de carácter heterogéneo. Áreas anaranjadas más compactas hacia el norte junto a una franja cenicienta y más suelta al sur. Cerámica relativamente abundante, con presencia de materiales de construcción -ladrillos romboidales, pintura mural, adobes y tejas- y abundantes carbones. Escasas piedras de pequeño y mediano tamaño.

Forma Dramont D 2, fase 3. Fragmento de borde y pico de mortero con labio de perfil prácticamente horizontal. Presenta una estría perimetral, que marca el inicio del vaso y que se prolonga lateralmente por el borde sobrealzado del pico. Conserva el inicio del cuerpo, de desarrollo hemisférico y pared interior recubierta de abundante abrasivo arenoso de grano medio. Arcilla fina de color rosado con áreas del núcleo algo más rojizas. Superficie beige de tacto untuoso. Desgrasante arenoso y calizo de grano medio poco abundante. Conservación: buena. Diámetro máx.: 40 $\mathrm{cm}$; diámetro boca: $27,5 \mathrm{~cm}$.
44. $\mathrm{N}^{\circ}$. de registro arq.: 11-16005-126. Se localizó en el mismo nivel arqueológico que el número 43 del catálogo.

Forma Dramont D 2, fase 3. Fragmento de ala de mortero, algo colgante con estría marcada al interior del vaso. Arcilla fina de color rosado amarillento y superficie untuosa de color pálido. Desgrasante compuesto por diminutas partículas doradas, rojas y negras. Conservación: regular. Diámetro máx.: $31,5 \mathrm{~cm}$; diámetro boca: $24 \mathrm{~cm}$.

45. $\mathrm{N}^{\mathrm{o}}$. de registro arq.: 11-16007-181. Nivel constructivo al sur del anfiteatro. Relleno suelto de tierra muy fina de color negruzco. Presencia de algunas piedras sobre todo en su extremo norte y de material de construcción -adobes, ladrillos romboidales y tejas-. En su mitad superior se identificaron abundantes materiales de cronología contemporánea, como envases, plásticos, pilas eléctricas y latas, que en cotas inferiores escasean hasta desaparecer. Material cerámico relativamente escaso, especialmente en cotas superiores. Este nivel se corresponde con el relleno interior de una cata realizada junto a la muralla en 1982.

Forma Dramont D 2. Fragmento de base de mortero plana indiferenciada. Pared interior de desarrollo hemisférico recubierta con una capa de desgrasante arenoso. Arcilla fina de color rosado pálido de tacto untuoso. Desgrasante con partículas doradas brillantes. Conservación: buena. Diámetro base: $23,5 \mathrm{~cm}$.

46. $\mathrm{N}^{\circ}$. de registro arq.: 11-16014-009. Nivel constructivo al sur del anfiteatro. Relleno fino y arenoso de color negruzco, suelto, sin apenas material cerámico.

Forma Dramont D 1. Fragmento de borde de mortero con ala colgante poco desarrollada y reborde en el extremo superior del vaso. Conserva el inicio de la pared, que parece de desarrollo hemisférico bastante abierto. Presenta abrasivo arenoso en la cara interna. Arcilla muy fina de color rosado rojizo con desgrasante de grano fino poco apreciable. Superficie con engobe de color blanco de tono amarillento. Conservación: regular. Diámetro máx.: $38 \mathrm{~cm}$; diámetro boca: $30 \mathrm{~cm}$.

47. $\mathrm{N}^{\mathrm{o}}$. de registro arq.: 11-16023-005. Nivel constructivo al sur del anfiteatro. Relleno heterogéneo de color grisáceo compuesto por tierra suelta de textura arenosa y algo de casquijo. Presencia de pellas de cal, carbones, cenizas, fragmentos de teja relativamente abundantes, pintura mural, ladrillos romboidales y rectangulares, adobes y abundante material cerámico.

Forma Dramont D 2, fase 3. Dos fragmentos de un mismo mortero que conserva la mitad del cuerpo, parte de la base y el pico vertedor. Presenta un ala desarrollada y ganchuda diferenciada del vaso por medio de una marcada estría. Cuerpo de desarrollo hemisférico y base plana indiferenciada. Pico definido por rebordes sobrealzados de trazado convergente remarcados lateralmente por profundas escotaduras y rematado de forma semicircular. Presenta un recubrimiento 

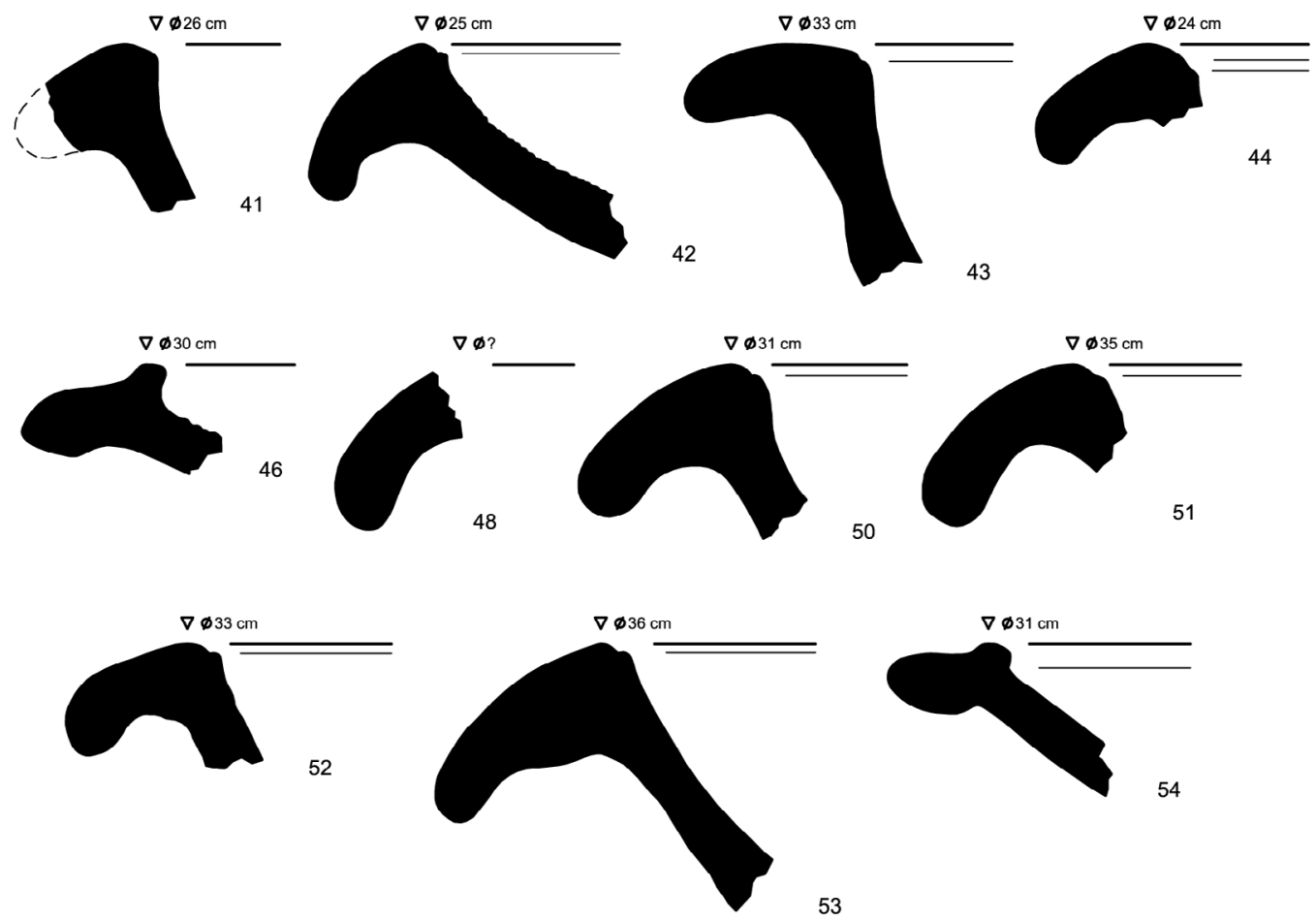

53
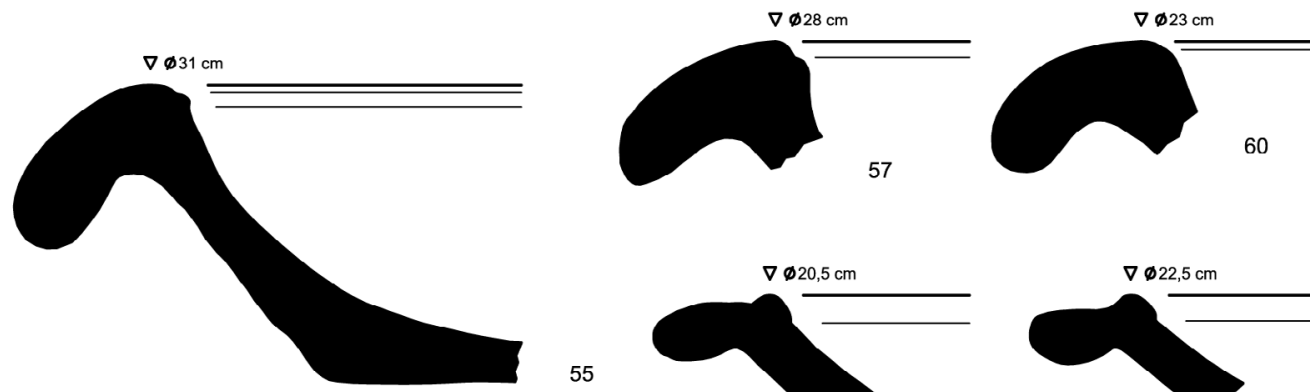

55
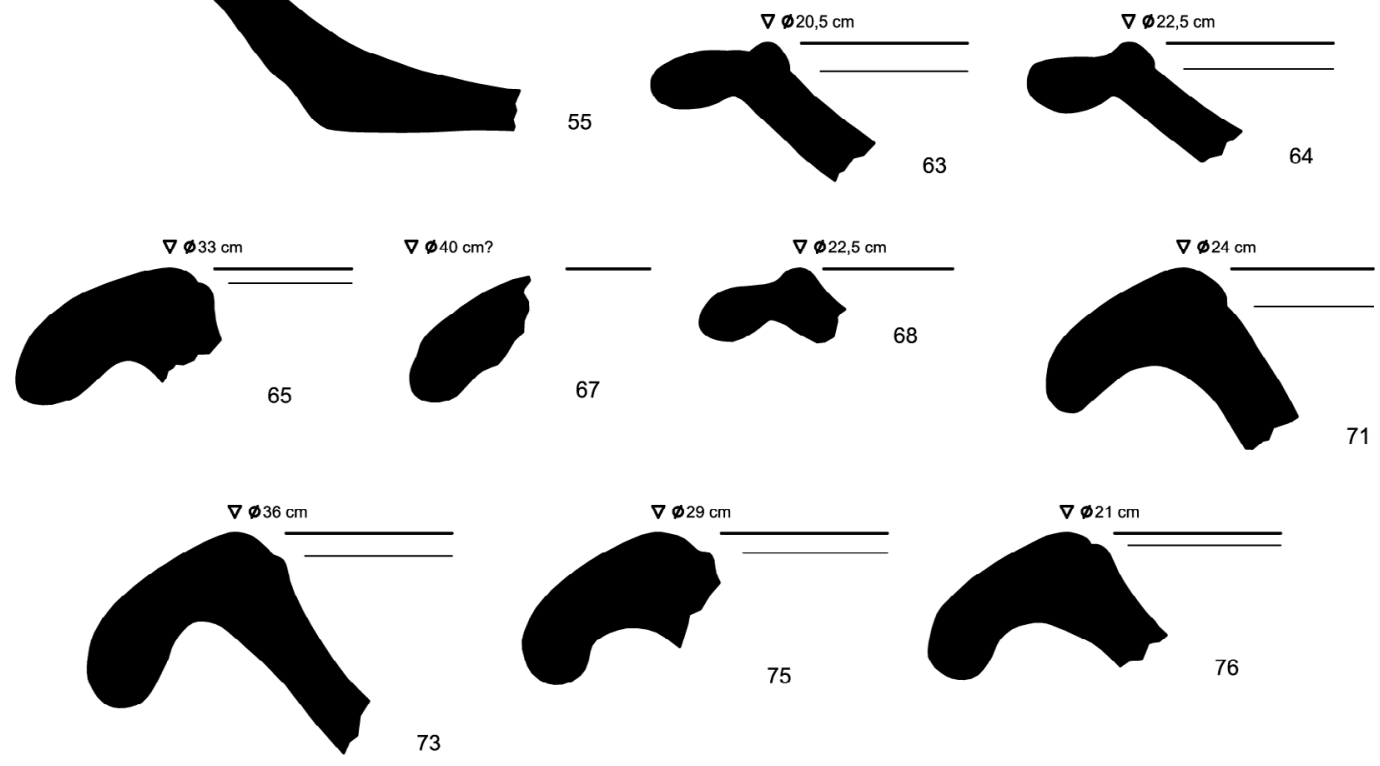

73

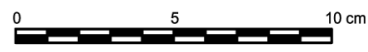

Figura 4: Perfiles de los morteros de producción centroitálica hallados en la excavación del anfiteatro de Segobriga. El número de la pieza corresponde al del catálogo.

abrasivo interno, de naturaleza arenosa. Pasta rosada rojiza de tacto algo rugoso con abundantes partículas brillantes diminutas. Superficie fina y lisa del mismo color que la pasta. Conservación: buena. Diámetro máx.: $38 \mathrm{~cm}$; diámetro boca: $30 \mathrm{~cm}$; diámetro base: $17,5 \mathrm{~cm}$. 
48. $N^{o}$. de registro arq.: 11-16023-581. Se localizó en el mismo nivel arqueológico que el número 47 del catálogo.

Forma Dramont D 2, fase 3. Fragmento de ala de mortero, de desarrollo muy ganchudo. No se conserva el borde. Arcilla rugosa de color amarronado con abundantes partículas doradas y granos de arena. Superficie exfoliada de tacto suave y color beige oscuro. Conservación: mala. Diámetro: no determinado.

49. $\mathrm{N}^{\mathrm{o}}$. de registro arq.: 11-16025-001. Nivel constructivo al sur del anfiteatro. Relleno de tierra arenosa y suelta de color blanquecino. Presencia áreas de gravilla fina y piedras medianas con raíces.

Forma Dramont D 2, fase 3. Fragmento correspondiente a la parte frontal de un mortero de cuerpo de desarrollo hemisférico rematado en un gran labio con ala colgante muy desarrollada. Una estría marca la unión del borde con el cuerpo que no presente abrasivo interno. El borde remata en un pico de forma troncocónica recto en su extremo frontal con rebordes convergentes sobrealzados remarcados por sendas escotaduras laterales. Arcilla muy fina de tacto algo áspero y color rosado rojizo. Desgrasante con partículas abundantes de color rojo y dorado. Superficie suave y lisa de color amarillento pálido. Conservación: muy buena. Diámetro máx.: 44,5 cm; diámetro boca: $34 \mathrm{~cm}$

Conserva las dos estampillas completas a ambos lados de la vertedera, en el que se repite el mismo texto. La cartela mide $2,5 \times 7,5 \mathrm{~cm}$. El texto del sello del lado derecho es convergente respecto a la vertedera y se lee desde el interior al exterior del borde. Tiene pérdida la esquina superior derecha. La altura de las letras es de $1 \mathrm{~cm}$. Presenta interpunción en forma de estrella de seis puntas en la $1^{\mathrm{a}}$ línea. Mientras el sello del lado izquierdo es divergente respecto a la vertedera y su desarrollo igual al anterior. Está fragmentado y no conserva la mitad inferior de la $2^{\mathrm{a}}$ línea. Presenta parte de la interpunción en forma de estrella. La altura de las letras es de $1 \mathrm{~cm}$.

Su texto dice:

\section{$S T(a t i) * M A R[c i]$ \\ SVAVIL[li]}

\section{Derecha}

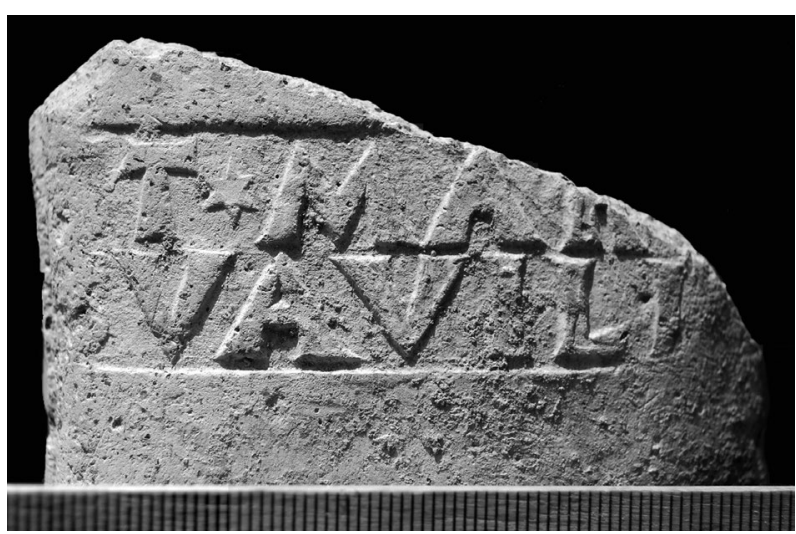

$[S t](a t i) * M A R C[i]$

[S]VAVIL[li]

izquierda

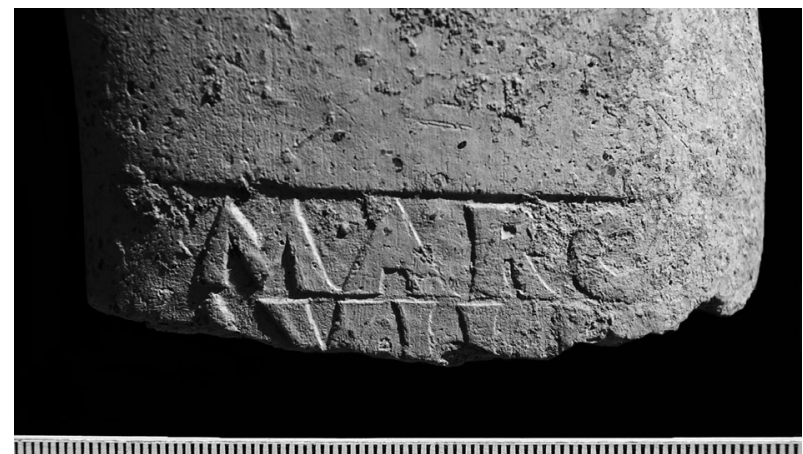

||||||||||||||||||||||||||||||||||||||||||||||||||||||||||||||||||||||||||||||||||||||||||||

Estos sellos nos proporcionan el nombre de un officinator desconocido hasta el momento en Hispania, sólo documentado en una estampilla circular sobre dolium procedente de Roma, decorada con una rama de palma (CIL XV 1291). Si conocemos a la familia a la que perteneció Svavilus, los Statii Marcii, que trabajaron en la figlina Marciana a partir del $30 \mathrm{~d}$. C. En otros dos sellos sobre morteros de Segobriga se menciona a un esclavo de Statius Marcius Celer, de nombre Quietius y a Restitutus, liberto de otro miembro de esta gens (Cebrián y Hortelano, 2011, $\mathrm{n}^{\mathrm{o}} .1$ y 29, 140). En la provincia Tarraconense encontramos dos sellos relacionados con esta familia, uno con mención a Quietius en la villa de Veïnat del Sant Crist en Cambrils y otro a St. Marcius Demetrius en Baetulo (Aguarod, 1991, 180). A ellos se une el hallazgo de un sello sobre mortero Dramont D 2 en el pecio de Ben-Afeli en Almazora en el que aparece otro esclavo de los St. Marcii, Primigenius (Ramos, Wagner y Fernández, 1984, 153 y fig. 13 c).

La difusión de los morteros sellados por los Statii Marcii fuera de Italia se concentra en la Galia Narbonense con estampillas de esta familia también en el pecio cap Dramont D (Hartley, 1973, 53). En Narbona se documenta a Statius Marcius Secundus (CIL XII, 5679.67) conocido en Roma (CIL XV, 2475a y b) y Pompeya (CIL X, 8048.42 a-d), donde como signo decorativo encontramos dentro de las estampillas un pámpano, un ramo y una estrella, esta última como en el ejemplar segobrigense.

50. $\mathrm{N}^{\circ}$. de registro arq.: 11-16025-624. Se localizó en el mismo nivel arqueológico que el número 49 del catálogo.

Forma Dramont D 2, fase 3. Tres fragmentos correspondientes al borde de un mortero de ala desarrollada y colgante con estría marcada en el borde del vaso que señala el inicio del cuerpo. Se conservan algunos restos en la cara interna de su recubrimiento abrasivo de naturaleza arenosa. Arcilla rosada oscura algo rojiza, fina, de tacto rugoso y con presencia de partículas rojas, doradas y granos de arena. Superficie lisa del mismo color que la pasta. Conservación: mala. 
Huellas de fuego. Diámetro máx.: $41 \mathrm{~cm}$; diámetro boca: $31 \mathrm{~cm}$.

51. $\mathrm{N}^{\circ}$. de registro arq.: 11-16025-625. Se localizó en el mismo nivel arqueológico que los números 49 y 50 del catálogo.

Forma Dramont D 2, fase 3. Fragmento de borde de mortero con gran ala ganchuda y estría que marca el inicio del vaso. Arcilla de tacto rugoso color rosado rojizo con abundante desgrasante formado por partículas rojas, doradas y negras brillantes. Superficie lisa del mismo color que la pasta. Conservación: regular. Diámetro máx.: 44,5 cm; diámetro boca: $35 \mathrm{~cm}$.

52. $\mathrm{N}^{\circ}$. de registro arq.: 11-16025-626. Se localizó en el mismo nivel arqueológico que los números 49,50 y 51 del catálogo.

Forma Dramont D 2, fase 3. Fragmento correspondiente al borde de un mortero con ala no excesivamente desarrollada de borde ganchudo. Presenta una marcada estría en el inicio del cuerpo, que conserva su recubrimiento abrasivo interno de tipo arenoso. Pasta muy fina de color rosado oscuro con partículas arenosas, calizas y doradas brillantes. Superficie lisa del mismo color. Conservación: buena. Diámetro máx.: $41 \mathrm{~cm}$; diámetro boca: $33 \mathrm{~cm}$.

53. $\mathrm{N}^{\circ}$. de registro arq.: 11-16043-371. Nivel constructivo al sur del anfiteatro. Relleno heterogéneo de tierra arenosa color marrón claro, suelta, con piedras relativamente abundantes, algunos fragmentos de adobe no muy numerosos y abundante material cerámico fragmentado. Áreas de textura gravosa.

Forma Dramont D 2, fase 3. Fragmento de borde de mortero con gran ala colgante remarcada por una estría que la diferencia en el borde del inicio del vaso. Arranque de las paredes del cuerpo, de desarrollo hemisférico, con la superficie interna recubierta por una capa de abrasivo arenoso muy desgastado. Arcilla de color amarronado grisáceo y tacto algo rugoso. Superficie lisa del mismo tono que la pasta. Desgrasante compuesto por abundantes partículas doradas. Conservación: buena. Diámetro máx.: 46,5 cm; diámetro boca: $36 \mathrm{~cm}$.

54. $\mathrm{N}^{\mathrm{o}}$. de registro arq.: 11-16045-1366. Nivel constructivo al sur del anfiteatro. Relleno de tierra arenosa, relativamente compacta, de color marrón grisáceo, con presencia de abundante ceniza y de carboncillos. Algunas piedras pequeñas, escasos fragmentos de teja y cerámica no demasiado abundante en comparación con los rellenos superpuestos.

Forma Dramont D 1. Fragmento de borde e inicio de cuerpo de un mortero con labio alargado horizontal ligeramente engrosado. Un reborde en forma de baquetón marca el inicio del cuerpo, de paredes exvasadas divergentes recubiertas por su cara interna por una capa de abrasivo arenoso. Pasta muy fina y depurada de color rosado. Superficie externa algo más pálida de tacto untuoso. Desgrasante inapreciable.
Conservación: buena. Diámetro máx.: $37,5 \mathrm{~cm}$; diámetro boca: $31 \mathrm{~cm}$.

55. $\mathrm{N}^{0}$. de registro arq.: 11-16045-1367. Se localizó en el mismo nivel arqueológico que el número 54 del catálogo.

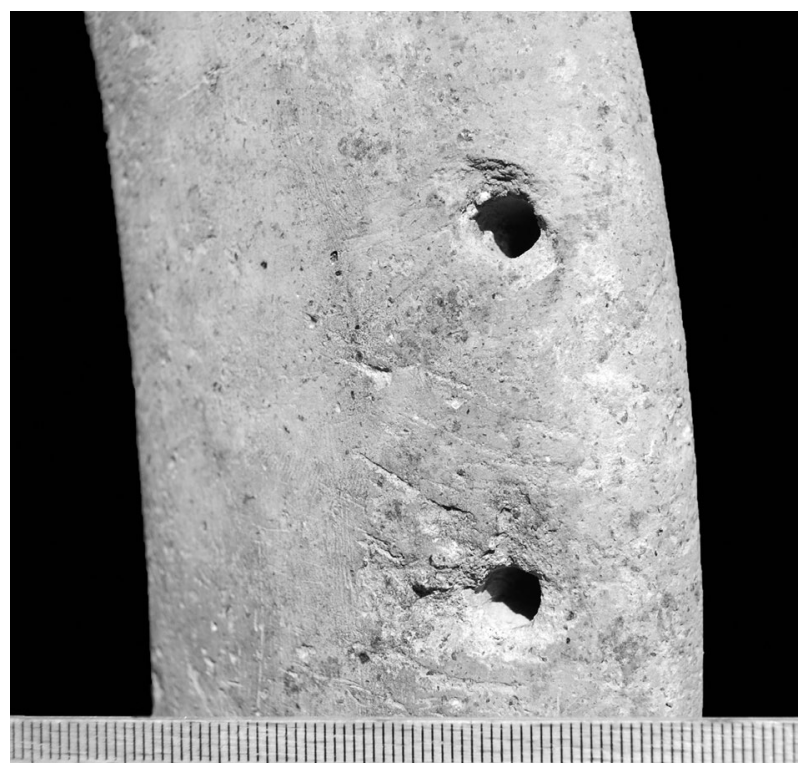

Forma Dramont D 2, fase 3. Fragmento de mortero que conserva parte de la base, pared y labio. Presenta una gruesa ala ganchuda diferenciada del cuerpo por medio de una estría bastante marcada en el extremo superior del vaso. Paredes de desarrollo hemisférico y base plana indiferenciada. Superficie interna recubierta por una capa de abrasivo arenoso algo erosionada en la parte central de la pieza. Pasta fina y homogénea de color rojizo con abundantes partículas brillantes, doradas y arenosas. Superficie muy lisa de tacto algo untuoso. Conservación: muy buena. Diámetro máx.: $39,5 \mathrm{~cm}$; diámetro boca: $31 \mathrm{~cm}$.

Conserva dos perforaciones postcochura en el labio, de sección circular, de $0,5 \mathrm{~cm}$ de diámetro, y separadas $3,4 \mathrm{~cm}$. Sirvieron para pasar un cordel y colgar el recipiente en la pared de una culina.

56. $\mathrm{N}^{\circ}$. de registro arq.: 11-16045-1368. Se localizó en el mismo nivel arqueológico que el número $55 \mathrm{del}$ catálogo.

Forma Dramont D 2. Fragmento de borde de mortero que conserva parte del inicio del pico vertedor con reborde sobrealzado. Ala fragmentada y pared interna con abrasivo arenoso algo erosionado. Pasta fina de color rosado rojizo con diminutas partículas de color dorado. Superficie lisa de tono algo más claro. Conservación: mala. Diámetro máx.: no determinado; diámetro boca: $32 \mathrm{~cm}$.

57. $\mathrm{N}^{\circ}$. de registro arq.: 11-16045-1369. Se localizó en el mismo nivel arqueológico que los números 55 y 56 del catálogo. 
Forma Dramont D 2, fase 3. Fragmento de borde de mortero con ala desarrollada colgante diferenciada de la pared del vaso por medio de una estría bastante marcada. Pasta fina algo rugosa con abundantes partículas doradas de pequeño tamaño. Superficie lisa y algo untuosa. Conservación: buena. Diámetro máx.: $37,5 \mathrm{~cm}$; diámetro boca: $28 \mathrm{~cm}$.

58. $\mathrm{N}^{\mathrm{o}}$. de registro arq.: 12-16046-086. Nivel constructivo al sur del anfiteatro. Tierra marrón grisácea, suelta y arenosa, con escaso material cerámico y poco material latericio.

Forma Dramont D 2. Fragmento de pico de mortero de desarrollo horizontal que conserva el borde derecho sobrealzado y ligeramente remarcado con una estría lateral. Pasta rojiza muy fina de tacto algo rugoso con diminutas partículas brillantes. Superficie lisa de color rosado pálido. Conservación: mala. Sólo se conserva la mitad del pico. Diámetro máx.: $33 \mathrm{~cm}$; diámetro boca: $22 \mathrm{~cm}$.

59. $\mathrm{N}^{\circ}$. de registro arq.: 12-16046-087. Se localizó en el mismo nivel arqueológico que el número 58 del catálogo.

Forma Dramont D 2, fase 3. Fragmento de borde de mortero. Conserva el arranque del ala, el inicio del cuerpo, remarcado por una estría bien definida y el inicio del pico, evidenciado en la estría divergente que enmarca su reborde sobrealzado. Arcilla fina amarronada con desgrasante dorado de grano muy fino. Superficie lisa del mismo color que la pasta. Conservación: muy mala. Diámetro: no determinado.

60. $\mathrm{N}^{\mathrm{o}}$. de registro arq.: 12-16049-094. Nivel constructivo al sur del anfiteatro. Relleno de tierra arenosa y suelta de color amarillento. Contiene abundantes fragmentos de adobe, piedras y numeroso material cerámico. También material de construcción, especialmente ladrillos rectangulares y restos de pintura mural.

Forma Dramont D 2, fase 3. Fragmento de borde de mortero correspondiente al inicio del pico. Presenta un ala gruesa y ganchuda diferenciada del cuerpo mediante una estría poco marcada. La pared interna del vaso se halla recubierta de abrasivo arenoso con evidentes signos de desgaste. en su extremo se aprecia el inicio de la profunda incisión que enmarcaría el reborde lateral del pico vertedor. Arcilla fina de tacto rugoso y color rosado oscuro. Abundantes partículas doradas de pequeño tamaño. Superficie lisa de color rosado. Conservación: regular. Superficie puntualmente quemada. Diámetro máx.: $32,5 \mathrm{~cm}$; diámetro boca: $23 \mathrm{~cm}$.

61. $\mathrm{N}^{\mathrm{o}}$. de registro arq.: 12-16051-464. Nivel constructivo al sur del anfiteatro. Relleno muy compacto de tierra grisácea con carboncillos. Textura arenosa muy fina, con escasas piedras, algunos fragmentos de teja y escasos adobes. Material cerámico relativamente poco abundante.
Forma no determinada. Fragmento correspondiente a la mitad izquierda del pico de un mortero. Presenta desarrollo horizontal y un reborde sobrealzado que forma el lateral del vertedor. Arcilla muy fina de color rosado muy pálido. Superficie lisa y untuosa. Desgrasante inapreciable. Conservación: mala. Sólo conserva la mitad del pico. Diámetro: no determinado.

62. $\mathrm{N}^{\mathrm{o}}$. de registro arq.: 12-16051-711. Se localizó en el mismo nivel arqueológico que el número 61 del catálogo.

Forma Dramont D 2. Fragmento correspondiente a la mitad inferior de un mortero de base plana y cuerpo de desarrollo hemisférico. Cara interna recubierta con abrasivo arenoso de grano medio bastante erosionado en la zona central. Pasta granulosa de tacto áspero y color amarronado claro de superficie lisa. Desgrasante compuesto por abundantes partículas doradas, arenosas y brillantes. Conservación: buena. Diámetro boca: $23 \mathrm{~cm}$.

63. $\mathrm{N}^{\mathrm{o}}$. de registro arq.: 12-16060-3099. Nivel constructivo al sur del anfiteatro. Tierra grisácea, suelta, con presencia de cenizas abundantes y carboncillos. Material cerámico muy abundante, con algunos fragmentos de teja y piedras pequeñas escasas. Hacia el muro exterior del anfiteatro (UE 16021) se documenta una mayor concentración de fragmentos de adobes y algunas piedras, caídos en favor de la pendiente natural del estrato.

Forma Dramont D 1. Fragmento de borde de mortero con ala prácticamente horizontal ligeramente engrosada, reborde en la parte superior del vaso que marca el inicio de la pared, de desarrollo hemisférico abierto y recubierta internamente por una capa de abrasivo arenoso con partículas doradas bastante espesa. Arcilla rosada clara muy fina de superficie amarillenta de tacto untuoso. Abrasivo inapreciable. Conservación: buena. Diámetro máx.: 27,5 cm; diámetro boca: $20,5 \mathrm{~cm}$.

64. $N^{o}$. de registro arq.: 12-16060-3100. Se localizó en el mismo nivel arqueológico que el número 63 del catálogo.

Forma Dramont D 1. Fragmento de borde de mortero de labio horizontal engrosado, reborde en el extremo superior de la pieza y arranque de la pared de desarrollo hemisférico algo abierto. Cara interna del vaso recubierta por una capa de abrasivo arenoso. Arcilla muy fina y depurada de color beige rosado de superficie algo más oscura y de tacto untuoso. Desgrasante compuesto por minúsculas partículas brillantes. Conservación: buena. Diámetro máx.: $29 \mathrm{~cm}$; diámetro boca: $22,5 \mathrm{~cm}$.

65. $\mathrm{N}^{\mathrm{o}}$. de registro arq.: 12-16060-3101 y 3102. Se localizó en el mismo nivel arqueológico que los números 63 y 64 del catálogo.

Forma Dramont D 2, fase 3. Dos fragmentos de un mismo mortero correspondientes al borde y parte del 
pico. Gruesa ala desarrollada de perfil colgante con estría marcada en la parte superior del vaso que la diferencia de la pared. Conserva la mitad del pico con reborde sobrealzado remarcado por una escotadura lateral. Arcilla fina de color rosado rojizo y superficie de tacto suave. Abundante desgrasante con partículas brillantes minúsculas y algunas rojizas. Conservación: regular. Diámetro máx.: 42,5 cm; diámetro boca: $33 \mathrm{~cm}$.

66. $\mathrm{N}^{\mathrm{o}}$. de registro arq.: 12-16060-4550. Se localizó en el mismo nivel arqueológico que que los números 63, 64 y 65 del catálogo.

Forma Dramont D 2. Fragmento de base plana indiferenciada de un mortero. Paredes de desarrollo hemisférico bastante profundas con abrasivo arenoso en la cara interna. Arcilla fina de color rosado pálido y tacto untuoso. Partículas doradas y negras brillantes. Conservación: buena. Diámetro base: $18 \mathrm{~cm}$

67. $\mathrm{N}^{\mathrm{o}}$. de registro arq.: 12-16062-002. Nivel constructivo al sur del anfiteatro. Relleno de tierra marrón arenosa y suelta con presencia de abundantes adobes fragmentados, con escasa presencia de cerámica.

Forma Dramont D 2, fase 3. Fragmento de ala de mortero de forma colgante. Arcilla fina y untuosa de color rosado claro con partículas doradas, negras brillantes y rojas. Diámetro máx.: $40 \mathrm{~cm}$.

68. $\mathrm{N}^{\mathrm{o}}$. de registro arq.: 12-16064-1023. Nivel constructivo al sur del anfiteatro. Relleno compacto de tierra arenosa de color grisáceo con presencia de algunos carboncillos. Material cerámico fragmentado relativamente abundante. Restos óseos de fauna.

Forma Dramont D 1. Fragmento de borde de mortero con ala engrosada y reborde vertical en la parte superior. Sólo conserva el arranque de la pared. Pasta muy fina de color rosado pálido y superficie amarillenta de tacto suave. Desgrasante prácticamente inapreciable. Conservación: regular. Diámetro máx.: 29 cm; diámetro boca: $22,5 \mathrm{~cm}$.

69. $\mathrm{N}^{\mathrm{o}}$. de registro arq.: 12-16065-002. Nivel constructivo al sur del anfiteatro. Capa de cenizas sueltas, homogéneas y finas, de color claro, veteadas por franjas de coloración más oscura. Presencia de áreas con abundante material cerámico.

Forma Dramont D 2, fase 3. Fragmento de mortero correspondiente a la mitad derecha de la pieza. Cuerpo de desarrollo hemisférico con base plana indiferenciada rematado en un labio muy desarrollado con ala ganchuda separada del vaso por medio de una profunda estría. Recubierto interiormente por una capa, algo erosionada, de abrasivo arenoso. Conserva la mitad del pico vertedor, de desarrollo horizontal, con reborde sobrealzado enmarcado por una escotadura lateral y rematado en forma semicircular. Arcilla fina de tacto rugoso de color beige amarillento. Desgrasante arenoso con partículas brillantes y doradas abundantes. Superficie lisa de color beige. Conservación: muy buena. Diámetro máx.: $38 \mathrm{~cm}$; diámetro boca: $28 \mathrm{~cm}$; diámetro base: $20 \mathrm{~cm}$.

Conserva sello completo en cartela, de $4 \times 7 \mathrm{~cm}$, localizado a la derecha del pico vertedor sobre el labio y dispuesto transversalmente a él, con lectura hacia el interior del mortero. El texto se distribuye en dos líneas, con letras de 1,3 y 1,4 cm de altura, respectivamente. El sello corresponde al punzón 18.35 de la clasificación de Pallecchi $(2002,139)$.

Su texto dice:

\section{$[P] R I S C V S \cdot D$ [uor] (um) \\ [D]OMITIOR [um]}

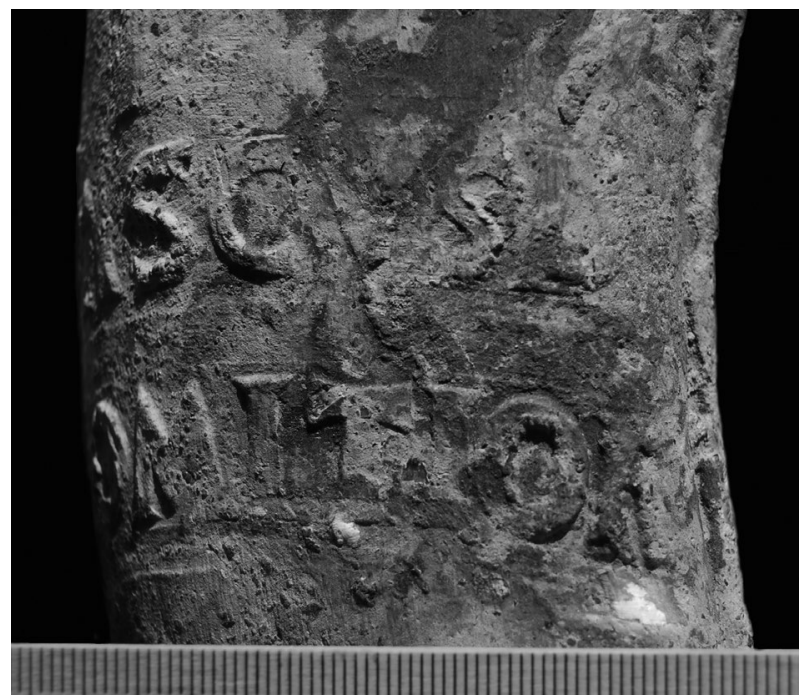

A Priscus, esclavo de Cn. Domitius Lucanus y Cn. Domitius Tullus, ya lo conocíamos en Segobriga, donde se documenta en otras dos estampillas sobre un mortero Dramont D 2, fase 3, hallado en las excavaciones realizadas en 1987 en el basamento de la puerta norte (Almagro-Gorbea y Lorrio, 1989, 153 y fig. 77; Cebrián y Hortelano, 2011, no. 2).

70. $\mathrm{N}^{\mathrm{o}}$. de registro arq.: 12-16065-003. Se localizó en el mismo nivel arqueológico que el número 69 del catálogo.

Forma Dramont D 2, fase 2. Fragmento correspondiente a la parte frontal de un mortero con ala bastante desarrollada muy colgante, prácticamente vertical, y pico horizontal de forma troncocónica definido por rebordes sobrealzados de trazado convergente remarcados con profundas escotaduras laterales. Remate frontal de forma semicircular. Arcilla de tacto muy rugoso de color anaranjado rojizo con abundante desgrasante de partículas arenosas, rojas, doradas y negras brillantes. Engobe liso de color amarillento. Conservación: muy buena. Diámetro máx.: $51 \mathrm{~cm}$; diámetro boca: $44 \mathrm{~cm}$.

Presenta sello completo en cartela, de 2,5 x 6,5 cm. El sello se sitúa en el borde del mortero con lectura desde el exterior al interior del recipiente. Está muy poco marcado y presenta restos de argamasa. La altura de las letras es de 1,1 y $1 \mathrm{~cm}$. Interpunción triangular 
con el vértice hacia arriba en la $2^{\mathrm{a}}$ línea. El sello corresponde al punzón 11.9 de la clasificación de Pallecchi $(2002,105)$.

El texto dice:

\section{[H]ERMETI(s)}

$[\mathrm{Fa}] \operatorname{VOR}($ is $) \cdot F($ ecit $)$

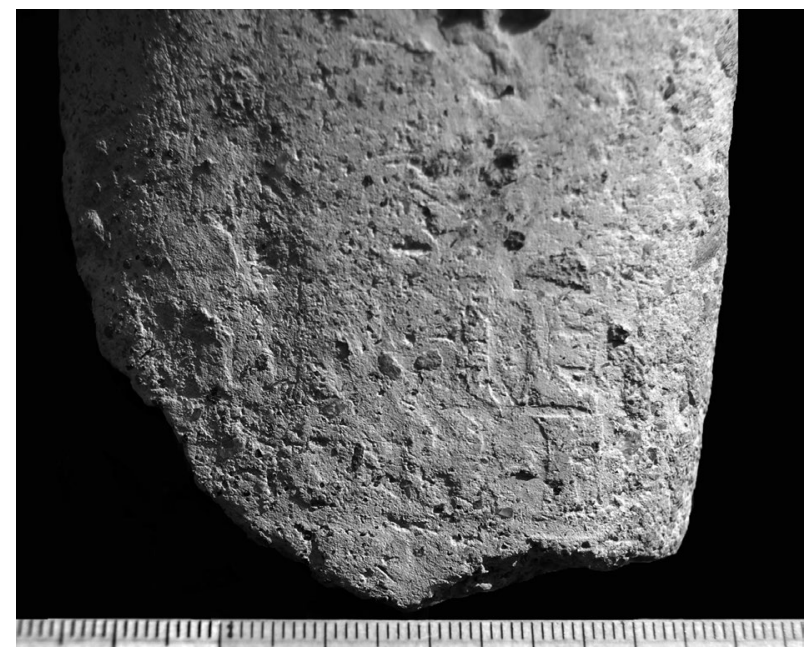

En la cartela del sello no queda espacio al principio de la $2^{\mathrm{a}}$ línea para la mención completa de $C$ (aius) Calp(etanus) Favor, de quien Hermes fue esclavo. $\mathrm{Su}$ nombre aparece delante de Favor lo que indica su condición social servil. Conocemos que durante la construcción de las termas de Trajano consiguió la manumisión, apareciendo en un sello sobre material latericio como C. Calpetani Hermetis (CIL XV, 321a), dato que nos proporciona una fecha ante quem para el trabajo de Hermes en la officina de este miembro de la familia de los Calpetanii, uno de los más importantes officinatores de las figlinae Marcianae (Piñol, López y Martí, 2000, 284-285).

Las estampillas de Hermes documentadas en Roma se fechan en época domicianea (Steinby 1974-75, 65), por lo que el ejemplar procedente de Segobriga constituye la evidencia más antigua de este esclavo de los Calpetanii, dada la datación de su contexto arqueológico, que no puede llevarse más allá del $70 \mathrm{~d}$. C.

Hermes se documenta en otro sello en Segobriga sobre un mortero Dramont D 2, fase 3, hallado en la plaza del foro en la campaña del año 2001 (Cebrián y Hortelano, 2011, nº.6).

71. $N^{o}$. de registro arq.: 12-16065-1943. Se localizó en el mismo nivel arqueológico que los números 69 y 70 del catálogo.

Forma Dramont D 2, fase 3. Fragmento de borde de un mortero con ala desarrollada colgante. Una estría marca la separación entre el labio y el inicio de la pared, cuya cara interna está revestida de una capa abrasiva arenosa. Arcilla rugosa de color marrón rojizo tostado. Superficie con engobe amarillento de tacto suave. Desgrasante arenoso con partículas negras brillantes. Conservación: buena. Diámetro máx.: 32,5 $\mathrm{cm}$; diámetro boca: $24 \mathrm{~cm}$.

72. $\mathrm{N}^{\mathrm{o}}$. de registro arq.: 12-16066-002. Nivel constructivo al sur del anfiteatro. Se halló en un relleno suelto y heterogéneo de color gris, de textura arenosa, con presencia de algunas piedras, tejas y restos de pintura mural y adobes disgregados.

Forma Dramont D 2, fase 3. Fragmento de borde de mortero con gran ala ganchuda e inicio del cuerpo, que presenta desarrollo hemisférico. Estría poco marcada en el extremo superior interno del recipiente, marcando el inicio del vaso. Arcilla de color rosado claro, con desgrasante compuesto por abundantes partículas doradas y rojas de grano fino. Diámetro boca: no determinado.

73. $\mathrm{N}^{\mathrm{o}}$. de registro arq.: 12-16066-004. Se halló en el mismo nivel arqueológico que el número 72 del catálogo.

Forma Dramont D 2, fase 3. Fragmento de borde de mortero de labio ganchudo muy desarrollado. Estría en el extremo superior interno del recipiente que marca el inicio del vaso que es de perfil hemisférico. Cara interna recubierta por una capa de abrasivo arenoso. Arcilla depurada de color rosado claro. Desgrasante compuesto por partículas de color dorado y rojo. Diámetro máx.: 45,2 cm; diámetro boca: $36 \mathrm{~cm}$.

74. $\mathrm{N}^{\mathrm{o}}$. de registro arq.: 11-16064-002. Nivel constructivo al sur del anfiteatro. Relleno compacto de tierra arenosa de color grisáceo con presencia de algunos carboncillos. Material cerámico fragmentado relativamente abundante y restos óseos de animales.

Forma Dramont D 2?. Fragmento del extremo frontal del pico vertedor, de bordes rectilíneos ligeramente colgantes. Arcilla fina y untuosa de color rosado pálido de superficie algo rugosa. Abundante desgrasante compuesto por partículas doradas, negras brillantes y rojizas. Diámetro boca: no determinado.

75. $\mathrm{N}^{\mathrm{o}}$. de registro arq.: 12-16089-078. Relleno constructivo de la summa cavea. Tierra marrón de textura arenosa con pequeñas piedrecitas. Textura algo vegetal, con raíces. Material cerámico bastante escaso.

Forma Dramont D 2, fase 3. Fragmento de borde mortero de ala muy ganchuda y amplia estría muy marcada en el inicio del vaso. Pasta granulosa de color rosado oscuro, fina, con abundante desgrasante dorado, rojo y arenoso. Superficie lisa de tacto suave. Conservación: regular. Diámetro máx.: $37,5 \mathrm{~cm}$; diámetro boca: $29 \mathrm{~cm}$.

Presenta sello en el interior de una cartela, de [2,5] x $7 \mathrm{~cm}$. El sello se sitúa en el borde del mortero, dispuesto en diagonal y con lectura del interior al exterior de la pieza. Una fractura ha provocado la pérdida de la mayor parte del texto de la primera línea y del motivo de hoja palma, que separa las dos líneas del sello. De la primera línea del texto conserva la parte inferior de las dos primeras letras, quizás una $\mathrm{C}$ y A,y el final de 
la línea con una D. La altura de las letras en la segunda línea es de $1,1 \mathrm{~cm}$.

Su texto dice:

\section{CA[llisti] D[u(orum)] $\dot{D} \dot{O M I T I O R}(\mathrm{um})$}

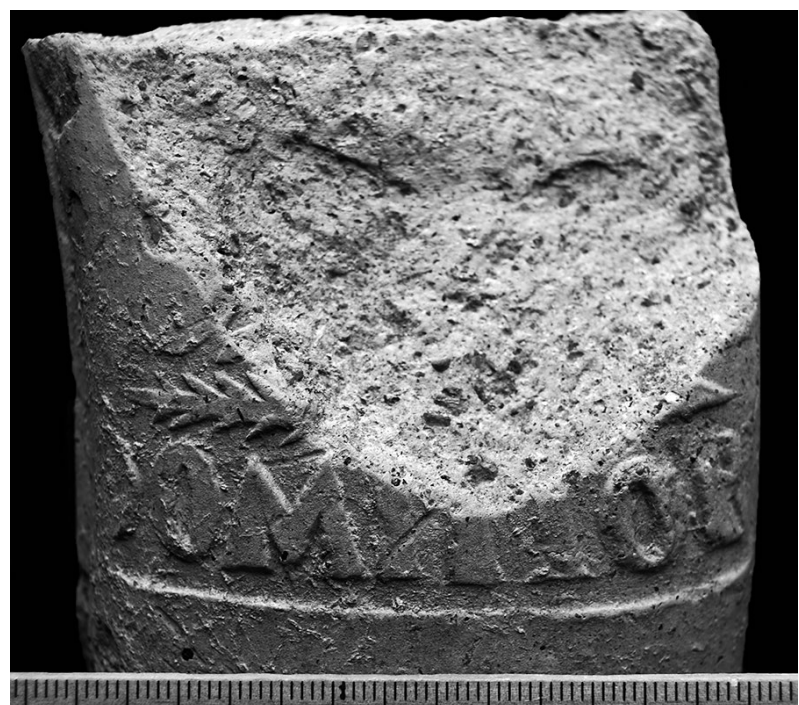

La figlina de los Domitii trabajó desde época augustea al tercer cuarto del siglo II d. C. (Gasperoni, 2005, 108). Entre los nombres de los esclavos de los hermanos Cn. Domitius Lucanus y Cn. Domitius Tullus, se encuentra Callistus, al que adscribimos este sello por ser el único conocido que comienza con las letras CA. Callistus aparece en ladrillos sellados en Roma, mencionando junto a su nombre duorum Domitiorum, que alude a aquellos (CIL XV, 992. 19, 2438). También se documenta en Ostia Antica (CIL XV, 992.20), Amiternum (CIL XV 992. 21), Antium (CIL XV, 992. 22) y Statonia en Etruria (CIL XV, $992.23=$ CIL XI, 6672.48).

A la muerte de Lucanus, acaecida el 93 dC, Callistus aparecerá mencionado sólo junto al nombre de $\mathrm{Tu}$ llus (CIL XV, 1004). De esta manera, ambos hermanos aparecerán juntos en las estampillas desde el año 59, fecha de la muerte de su padre adoptivo Cn. Domitius Afer, hasta el 93 (Aguarod, 1991, 155).

76. $\mathrm{N}^{\mathrm{o}}$. de registro arq.: 12-16090-011. Relleno constructivo de la summa cavea. Tierra grisácea bastante suelta de textura arenosa con presencia de carboncillos.

Forma Dramont D 2, fase 3. Fragmento de borde de mortero con gran ala colgante y estría muy marcada en el reborde superior del vaso. Arranque del cuerpo con restos de abrasivo arenoso en la pared interna. Pasta rugosa de color rojizo con abundante desgrasante (partículas doradas, negras y rojas). Superficie fina y lisa algo untuosa de color rosado rojizo. Conservación: buena. Diámetro máx.: $30 \mathrm{~cm}$; diámetro boca: $21 \mathrm{~cm}$.

77. $\mathrm{N}^{\mathrm{o}}$. de registro arq.: 12-16112-207. Se halló en una fosa de expolio de los sillares de una de las puertas de acceso a la summa cavea del graderío sur del anfiteatro ( $4^{\circ}$ vomitorio). Relleno suelto y heterogéneo de tierra marrón con piedras y materiales de construcción y poca presencia de material cerámico.

Forma Dramont D 2, fase 3. Fragmento de mortero que conserva parte de la base, pared, labio y pico vertedor. Presenta un ala muy colgante, de aspecto ganchudo diferenciada del cuerpo por una estría poco marcada al inicio del vaso y pico vertedor de forma troncocónica con reborde sobrealzado y escotaduras laterales. Paredes de desarrollo hemisférico y base plana indiferenciada, con la superficie interna recubierta por una capa de abrasivo arenoso bastante erosionada en el fondo de la pieza. Arcilla áspera de color rosado rojizo de superficie rosada de tacto fino y untuoso. Desgrasante con partículas brillantes y rojas. Conservación: muy buena. Diámetro máx.: $34 \mathrm{~cm}$; diámetro boca: $27,5 \mathrm{~cm}$; diámetro base: $17,5 \mathrm{~cm}$.

Conserva sello completo en cartela, de $3,2 \times 6 \mathrm{~cm}$, localizado a la derecha del pico vertedor. Su lectura es convergente respecto a la vertedera y se realiza desde el interior al exterior del borde. El sello se encuentra muy erosionado y presenta una fuerte concreción calcárea sobre su superficie, lo que impide su lectura completa. El texto se distribuye en dos líneas, con letras de $1,3 \mathrm{~cm}$ y 1,2 cm de altura. El sello corresponde al punzón 39.2 de la clasificación de Pallecchi $(2002,202)$.

Su texto dice:

\section{$S(t) M A R[c i]$}

[D]EMET[ri]

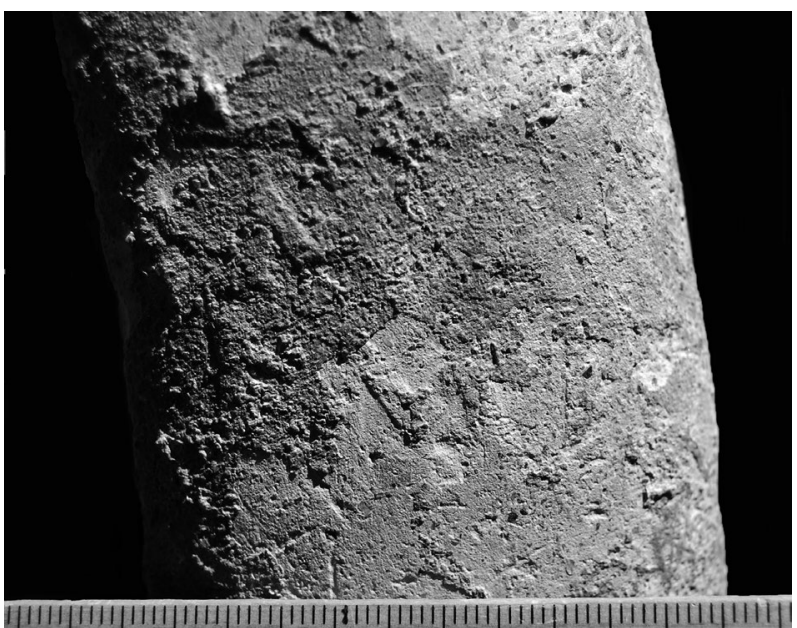

El officinator Statius Marcius Demetrius, fue un liberto de Statius Marcius Helenus (CIL XV S. 335 corr.: Stati Marci Heleni Demetrius s(ervus) f(ecit). Su nombre se documenta en varias estampillas sobre morteros hallados en Roma, mencionado en nominativo y acompañado de la abreviatura $\mathrm{F}$ del verbo fecit ((CIL XV 1273a, b y c), fechados en época vespasianea, aunque C. Lega y M. Valenti $(2015,159)$ llevan la cronología de uno de ellos a época julioclaudia (CIL XV 1273 a). También aparece en genitivo en un sello sobre otro mortero de Roma (CIL XV 2460), como en el ejemplar 
segobrigense. En Hispania, otro mortero con su marca está atestiguado en Baetulo (Aguarod, 1991, 171, n. 14).

\section{LA COMERCIALIZACIÓN DE LOS MORTE- ROS DRAMONT D 2 EN SEGOBRIGA}

Los beneficios obtenidos de la comercialización del lapis specularis propiciaron en Segobriga un desarrollo urbano importante, que se inició a mediados del siglo I a. C. En esas fechas, aún como oppidum stipendiarium, comenzó a emitir moneda y envió una legación a Roma para rendir homenaje a L. Livius Ocella, el abuelo del futuro emperador Galba, en su condición de quaestor provinciae Hispaniae citerioris y patrono de los segobrigenses (Alföldy, CIL VI/8.3, p. 4699, ad n..$^{\circ}$ 1446a).

De la explotación y comercio del yeso traslúcido surgieron familias indígenas enriquecidas que, a partir de época augustea, participaron en la financiación de su espacio público; entre ellos Proculus Spantamicus, que asumió el coste del material empleado en la pavimentación de la plaza (forum sternundum de sua pecunia) y [Ant]onia Arganta y M. Iulius [--] (de sua pecunia), que pagaron la exedra del edificio construido junto al pórtico septentrional (Abascal, Alföldy y Cebrián, 2011, nº 31 y 32).

Las familias más importantes de la sociedad segobrigense controlaron la vida económica de la ciudad y ostentaron muy pronto importantes cargos públicos en ella. Con, al menos, trece senadores a partir de época de Claudio, como los Octavii, que financiaron la decoración de la frons scaenae del teatro, fue la única ciudad de la Celtiberia que contó con representación en el Senado romano (Alföldy, 2011, 388-340). Sólo la riqueza generada por el lapis specularis podría explicar la fuerte proyección exterior que tuvo la ciudad en el siglo I d. C.

La mayor parte de este material se exportó a través del puerto de Carthago Nova, su capital conventual, con el que le unía una vía directa que pasaba por la ciudad en dirección a Complutum. La actividad comercial de Segobriga debió ser significativa como principal nudo de comunicaciones en el interior peninsular; por ella transitaba también la calzada que desde el valle del Ebro entraba en la Meseta por Ercavica, en dirección a la Betica y Lusitania y la que desde Toletum se dirigía por Valeria a los puertos levantinos.

Carthago Nova, la ciudad púnica convertida en colonia romana a mediados del siglo I a. C., era un emporio comercial en el Mediterráneo con un puerto que se convirtió en el principal centro receptor y redistribuidor de mercancías procedentes de puertos italianos, orientales y norteafricanos y salida de la producción metalúrgica y salazones del sureste y lapis specularis y cereal del interior de Hispania.

El lote de materiales cerámicos descubierto en el vertedero del anfiteatro de Segobriga revela la llegada a la ciudad, a mediados del siglo I d. C., de vajilla fina de la Gallia y cerámica de cocina de origen itálico -morteros Dramont y producciones de engobe rojo pompeyano-, junto con vinos elaborados en Italia y el Mediterráneo Oriental y frutos secos del área siriopalestina. También están presentes los productos hispanos, como vinos béticos y layetanos, aceite del valle del Guadalquivir y salazones de la costa andaluza.

La presencia significativa de terra sigillata gálica $(90,91 \%)$, en detrimento de las producciones más tempranas de terra sigillata hispánica $(4,85 \%)$ sugiere la llegada al puerto de Carthago Nova y su posterior traslado por tierra hasta el interior peninsular, de barcos procedentes del puerto de Narbo, cuya actividad comercial se desplegó durante época altoimperial como centro redistribuidor de mercancías procedentes de distintos puntos del Mediterráneo. Además, el conjunto de 256 sellos sobre cerámica gálica atestiguados en las excavaciones llevadas a cabo en el anfiteatro segobrigense corresponden, al menos, a un centenar de alfareros distintos de La Graufesenque, exportados por aquel puerto a toda la cuenca mediterránea. Entre ellos, Bassus, Crestio, Modestus, Secundus, Silvanus y Vitalis documentados también en los rellenos de nivelación de la plaza del Hospital de Cartagena, junto al anfiteatro, con una cronología entre 60-70 d. C. (Castellano, 2000, 158-160)

Está atestiguado el comercio marítimo del aceite bético hacia la provincia de la Gallia Narbonensis utilizando la ruta Hispalis - Baleares - Narbo y Arelate para su posterior redistribución (Berni, 1998, 70-76; Garrote, 2003, 227), mientras que otra ruta partía del sur de Hispania jalonando la costa mediterránea peninsular hasta los principales puertos redistribuidores de la costa francesa y, al contrario, descendiendo por el litoral levantino hacia la Bética desde Narbo (Ramallo, 1989, 76). En esta ruta comercial, las instalaciones portuarias de Carthago Nova permitieron almacenar las mercancías, que se redistribuyeron con posterioridad hacia otros puertos menores del litoral y hacia el interior de Hispania por la vía que se dirigía a Complutum, tal y como describe Estrabón (III, 4, 6): «el mayor emplazamiento comercial de las mercancías llegadas por mar para las gentes del interior y de los productos locales para los del exterior» (Ramallo y Martínez Andreu, 2010,155).

La orientación de Segobriga como centro de control del comercio con el Mediterráneo en el interior de la Meseta explicaría la llegada masiva de productos itálicos, galos, orientales y desde otras zonas de Hispania, como los vasos engobados de paredes finas del valle del Ebro, ánforas de vino, aceite y salazones béticos y vino de la tarraconense. Mientras los intereses comerciales de algunos miembros de sus elites se confirmaría por la presencia en Narbo de Caius Iulius Italus, de origo segobrigens(is) y perteneciente al ordo equester (CIL XII 4536), el cual se desplazó a la ciudad gala a inicios de época augustea.

El número de sellos de los Statii Marcii documentados en Segobriga en relación a los escasos ejemplares conocidos en el resto de Hispania que, además, 
se concentran en la costa noreste, podría relacionarse con la llegada de morteros desde la Galia Narbonense, donde son frecuentes las estampillas de esta familia.

El conjunto de morteros Dramont D 2 hallados en las excavaciones realizadas en el anfiteatro se fechan entre finales de época de Claudio y el reinado de $\mathrm{Ne}$ rón, coincidiendo con el momento de mayor intensidad de la actividad comercial y económica en la ciudad, que se exteriorizará en la construcción de los dos grandes edificios para espectáculos, teatro y anfiteatro.

El declive a finales del siglo I d. C. de la actividad mercantil vinculada a las minas de lapis specularis conllevará un cambio de los flujos comerciales, ya no tan vinculados a Carthago Nova sino a las rutas de distribución en el interior peninsular. En los contextos cerámicos del siglo II en la ciudad se aprecia una drástica disminución de las importaciones del Mediterráneo, manifestada en la escasez de recipientes anfóricos $\mathrm{y}$, sobre todo, de productos norteafricanos.

\author{
Profa. Dra. Rosario Cebrián Fernández \\ Dpto. de Ciencias y Técnicas \\ Historiográficas y de Arqueología \\ Facultad de Geografía e Historia \\ C/ Profesor Aranguren, $s / n$ \\ Universidad Complutense \\ Ciudad Universitaria \\ 28040 Madrid \\ marcebri@ucm.es \\ Ignacio Hortelano Uceda \\ Parque Arqueológico de Segobriga \\ 16430 Saélices \\ ignacio.hortelano@gmail.com
}

\section{BIBLIOGRAFÍA}

ABASCAL, J. M., ALFÖLDY, G. y CEBRIÁN, R., 2011: Segobriga V. Inscripciones romanas (1986-2010), Madrid.

ABASCAL, J. M. y CEBRIÁN, R., 2007: «Carthago Nova como caput viae. Dos miliarios de Huelves (Hispania citerior) », Zeitschrift für Payrologie und Epigraphik, 162, 257-262.

AGUAROD OTAL, C., 1991: Cerámica romana importada de cocina en la Tarraconense, Zaragoza.

ALFÖLDY, G., 1987: Römisches Städtewesen auf der neukastilischen Hochebene. Ein Testfall für die Romanisierung, Heidelberg.

ALFÖLDY, G., 2011: «XI. Apéndice. Nuevos senadores, la inscripción dedicatoria del teatro y la aristocracia senatorial de Segobriga», en J.M. Abascal, G. Alföldy y R. Cebrián, Segobriga V. Inscripciones romanas (19862010), Madrid.

ALMAGRO-GORBEA, M. y LORRIO, A. J., 1989: Segobriga III. La muralla norte y la puerta principal, Cuenca.

BELTRAN LLORIS, M., 2002: «Un rasgo de la colonización itálica: la fabricación de morteros en la Hispania tardorrepublicana (valle del Ebro)», Vivre, produire et échanger: reflets méditerranéens, Mélanges offerts à Bernard Liou, Archéologie et Histoire Romaine 8, 275-286.
BELTRÁN LLORIS, M., 2003: «Los morteros bilingües del valle del Ebro», Palaeohispanica, 3, 59-71.

BERNI, P. 1998: Las ánforas de aceite de la Bética y su presencia en la Cataluña romana, Col.lecció Instrumenta 4, Barcelona.

CASTELLANO, J. J., 2000: «La terra sigillata sudgálica del área del anfiteatro romano de Carthago Nova», Saguntum, 32, 151-168.

CEBRIÁN, R. y HORTELANO, I., 2011: «Los morteros centroitálicos de Segobriga», Lucentum, 30, 127-142.

DOSI, A. y SCHNELL, F., 1984: A tavola con $i$ Romani Antichi, Roma.

GASPERONI, T., 2003: Le fornaci dei Domitii. Ricerche topografiche a Mugnano in Teverina, Daidalos 5, Viterbo.

GARROTE, E., 2001: «Los puertos de Narbo Martius y Arelate, y su relación con los circuitos comerciales del aceite bético», en P. Berlanga y J. Pérez Ballester (eds.), Puertos fluviales antiguos: ciudad, desarrollo e infraestructuras. IV Jornadas de Arqueología Subacuática (Valencia, 2001), 227-235, Valencia.

HARTLEY, F., 1973: «La diffusion des mortiers, tuiles et autres produits en provenance des fabriques italiennes», Cahiers d'archéologie subaquatique, II, 51-57.

LEGA, C. y VALENTI, M., 2015: «Bolli laterizi dall'ager tusculanus: nota preliminare », en M. Spanu (ed.), Opus Doliare Tiberinum, Atti delle Giornate di Studio (Viterbo, 25-26 octubre 2012), Daidalos 15, 135-170, Viterbo.

PALLECCHI, S., 2002: I mortaria di produzione centroitalica. Corpus dei bolli, Roma.

PEINADO, Ma . V., 2011: «Mortaria Baeticae. La producción de morteros en la Bética durante el Alto Imperio, Cuadernos de Prehistoria y Arqueología de Granada, 21, 283-302.

PIÑOL, L., LOPEZ, J. y MARTI, G., 2000: «C. Calpetanus Hermes i la difusió de materials ceràmics de construcció de les figlinae urbanes de Roma a Tarraco», Empùries, 52, 281-288.

RAMALLO, S. F., 1989: La ciudad romana de Carthago Nova: La documentación arqueológica, en La ciudad romana de Carthago Nova: Fuentes y materiales para su estudio, 2, Murcia.

RAMALLO, S. F. y MARTÍNEZ ANDREU, M., 2008: «El puerto de Carthago Nova: eje de vertebración de la actividad comercial en el sureste de la Península Ibérica», XVII International Congress of Classical Archaeology, 141-159, Roma,

RAMOS, J. E., WAGNER, J. y FERNÁNDEZ, A., 1984: «El yacimiento arqueológico submarino de Ben-Afeli. Estudio de los materiales (Almazora, Castellón)», Cuadernos de Prehistoria y Arqueología Castellonenses, 10, 121-158.

STEINBY, M., 1974-1975: «La cronologia delle figlinae doliari urbane dalla fine dell'età repubblicana fino all'inizio del III secolo», Bollettino della Commissione Archeologica Comunale di Roma, 84 (1974-75, publicado en 1977), 7-132.

Recepción: 30-05-2016 Aceptación: 19-07-2016 